\title{
Erratum to: Occurrence of arbuscular mycorrhizal fungi in saline soils of the Tabriz Plain of Iran in relation to some physical and chemical properties of soil
}

\author{
N. Aliasgharzad ${ }^{1} \cdot$ N. Saleh Rastin ${ }^{2} \cdot$ H. Towfighi ${ }^{2} \cdot$ A. Alizadeh $^{3}$
}

Published online: 11 April 2017

(C) Springer-Verlag Berlin Heidelberg 2017

Erratum to: Mycorrhiza (2001) 11:119-122

DOI10.1007/s005720100113

The original version of this article, unfortunately, contained error. The family name of the corresponding author was incorrectly spelled as "Aliasgharzadeh". The correct spelling is "Aliasgharzad" and is now presented correctly in this article.

The online version of the original article can be found at http://dx.doi.org/ $10.1007 / \mathrm{s} 005720100113$

N. Aliasgharzad

n-aliasghar@ark.tabrizu.ac.ir

1 Department of Soil Science, Faculty of Agriculture, University of Tabriz, Tabriz 51664, Iran

2 Department of Soil Science, Faculty of Agriculture, University of Tehran, Karaj, Iran

3 Department of Plant Pathology, Faculty of Agriculture, University of Tarbiat Modarres, Tehran, Iran 